\title{
O PLANEJAMENTO REGIONAL FRANCÊS EM MEADOS DO SÉCULO XX: O IMPACTO DA OBRA PARIS ET LE DÉSERT FRANÇAIS DE JEAN-FRANÇOIS GRAVIER
}

\author{
Breno Viotto Pedrosa \\ Universidade Federal do Rio Grande do Sul
}

\begin{abstract}
Resumo
Este artigo se vale de uma abordagem contextualista para compreender quais são os argumentos centrais da obra Paris et le désert français de Jean-François Gravier. Considerando o contexto social e os livros que vieram após a publicação de Paris... se busca explorar quais foram as influências intelectuais de Gravier, sua linha de argumentação e método, delineando paralelamente qual foi seu papel no corpo administrativo do planejamento regional francês. Conclui-se que apesar de sua obra apresentar fragilidades do ponto de vista científico, por meio da defesa da desconcentração urbano industrial ela auxiliou a fortalecer o planejamento regional na França, repercutindo na elaboração de políticas de Estado e no campo científico da geografia.
\end{abstract}

Palavras-chave: Desconcentração urbano-industrial; Jean-François Gravier; Planejamento Regional.

\begin{abstract}
This article uses a contextual approach to understand the central arguments of Jean-François Gravier's Paris et le désert français. Considering the social context and the books that came after the publication of Paris..., we seek to investigate the intellectual influences of Gravier, his arguments and method, outlining in parallel his role in French regional planning administrative institutions. We concluded that although the scientific weaknesses of his works, is clear the defense of industrial urban deconcentration which helped to strengthen regional planning in France, affecting the elaboration of State policies and the geographic scientific field..
\end{abstract}

Key words: Urban-industrial deconcentration; JeanFrançois Gravier; Regional Planning.

A reafirmação do planejamento regional no seio do Estado francês foi um processo lento, cheio de avanços e retrocessos. O papel de Gravier nesse processo foi importante e não seria exagero relacionar a publicação do livro Paris et le désert français à institucionalização do planejamento. Após a criação de órgãos menores e a publicação de diversos tipos de planos - que nem sempre foram completamente executados -, o planejamento regional teve seu momento áureo com a fundação da Délégation interministerièlle à l'aménagement du territoire (DATAR), em 1963. Dessa forma, se observa no transcurso do século XX a consolidação de um campo (BOURDIEU, 2003) ao redor do tema do planejamento regional com engenheiros, geógrafos, urbanistas e economistas que começam a propor planos de ação e, gradualmente, ganham capital institucional no campo do Estado, consolidando sua posição na burocracia $^{1}$.

\footnotetext{
${ }^{1}$ Todas as traduções do texto são nossas no caso de referências em língua estrangeira.
} 
O Estado e a sociedade francesa se depararam com demandas sociais que exigiram a organização de um sistema de planejamento territorial face aos adventos da Primeira e da Segunda Guerra Mundial. Assim, a obra de Gravier é relevante, pois foi capaz de convencer parte da classe dirigente que a exacerbada concentração populacional, industrial, de comércios e serviços em Paris foi prejudicial para a nação como um todo, sendo necessária a ação do Estado para reequilibrar o território, permitindo revitalizar a França, que, na sua opinião, era decadente nas décadas de 1920 e 1930. Nesse artigo, aspiramos analisar a trajetória de Gravier, delinear os argumentos centrais de Paris... e identificar seus principais impactos na França. Para tanto, utilizamos o método contextual que admite a necessidade de se analisar a démarche do autor estudado, a partir de suas opções de método, de seu contexto histórico, da atmosfera intelectual em que ele se insere, bem como de suas redes de relações, sejam elas acadêmicas, sejam políticas (BERDOLAY, 2003).

\section{A trajetória de Gravier}

Jean-François Gravier (1915-2005) foi geógrafo influenciado por Vidal de la Blache e seus discípulos, dando valor à ideia de região, seja como escala de ação política, seja como conceito de análise do espaço geográfico. Formando na Sorbonne, Gravier obtém a agrégation em história e geografia (COUZON, 2003, p. 85). Na juventude, Gravier participou da L'action française e, posteriormente, da Jeune droite, ambos grupos políticos de direita. Em 1936, ele colaborou na revista Combat de Jean Fabrègues e Thierry Maulnier, ambos católicos sob influência do círculo Proudhon que "[...] em 1911, tentou combinar o nacionalismo de Maurras, o socialismo de Proudhon e o sindicalismo revolucionário de Sorel" (AUZÉPY-CHAVAGNAC, 1995, p. 92). Em 1939, junto a François Perroux, Gravier era editor da revista Civilisation e, em 1941, colaborou na revista Idées (COUZON, 2003, p. 85). Nesse contexto, Gravier leu Charles Maurras - inspirador da l'action française -, um jornalista, ensaísta e poeta, cujas ideias influenciaram grupos de direita e o próprio regime de Vichy, liderado pelo marechal Pétain durante a ocupação alemã da França no início da Segunda Guerra Mundial.

Maurras foi um antidreyfussard ${ }^{2}$ que forjou uma doutrina de defesa do monarquismo, da religião católica, do nacionalismo, do federalismo, do anitparlamentarismo e da descentralização política da França, inspirando, dentre outros, grupos fascistas (WINOCK; JULLIARD, 1996, p. 773). Contudo, sua influência na obra científica de Gravier aparece de forma discreta. Talvez os fatos mais marcantes sejam sua insistência sobre a defesa nacional através do desenvolvimento econômico e demográfico, bem como na descentralização por meio do descongestionamento de Paris e da autonomização das regiões francesas. A descentralização de Maurras (2008) se apoia em um sistema federalista formado pelas unidades regionais, cujo elemento unificador é a história nacional, bem como a língua, a raça, a religião católica, a cultura e as relações comerciais. Assim, o federalismo é uma divisão do trabalho político que confere liberdade às províncias e às cidades. Maurras também chama atenção para os desenraizados, fruto do êxodo rural que esvazia as

\footnotetext{
${ }^{2}$ Grupo que se opunha à causa do capitão Alfred Dreyfus, militar de origem judaica acusado de traição em um processo judicial baseado em documentos falsos.
} 
regiões interioranas e lotam Paris (MAURRAS, 2008, p. 47-50). Todas essas problemáticas tocam Gravier e são abordadas em suas obras.

Entre 1940 e 1941, Gravier trabalhou na Universidade de Belgrado, mas, em 1941, é convidado para integrar a Secretaria Geral da Juventude e, em 1942, a Fundação Alexis Carrel (PRITCHARD, 2011, p. 312), órgão que foi para o regime de Vichy uma instituição produtora de análises, ideologias, planos e estratégias de desenvolvimento. $\mathrm{Na}$ época, o economista François Perroux era o dirigente da Fundação (WINOCK; JULLIARD, 1996, p. 428).

O envolvimento político de Gravier é relevante, pois ele encontra aí uma rede de apoio que impulsiona seu acúmulo de capital cultural. Na Fundação Carrel, Gravier fica responsável pelo departamento de síntese regional, ou seja, pela organização de monografias sobre províncias da França (COHEN, 2006, p. 581). Em plena guerra, Gravier (1942) publica Régions e Nation, por encomenda de F. Perroux para compor uma coleção que buscava difundir ideias do regime. Nessa ocasião, ele expõe a fragilidade do pacto nacional francês diante das províncias que se encontram cada vez mais vazias, com recursos ociosos, e da grande Paris que drena mão de obra e recursos a favor de interesses econômicos, nem sempre coincidentes com os nacionais. $O$ livro busca estudar e restituir historicamente as regiões (pays) a fim de identificar suas potencialidades visando o renascimento nacional (COUZON, 2003, p. 85).

Do ponto de vista ideológico, o regime Vichy pregava a valorização das regiões, dos camponeses e da unidade familiar, um ideário conversador que se resume no mote "retorno ao campo", na medida em que a revolução nacional integral significaria, dentre outras coisas, a valorização do mundo rural em detrimento das cidades. Contudo, como demonstra Paxton (1972), a elite política e econômica de Vichy estava longe de ser um bloco homogêneo. Nesse contexto, circulava a visão de que a França era decadente em função da retração demográfica e do crescimento das cidades que consolidam uma comunidade impessoal e cosmopolita, contrária à vida orgânica do campo (PAXTON, 1972, p. 33). Além disso, a crítica ao liberalismo, ao parlamentarismo e à sociedade de massas estavam na ordem do dia.

Se uma parcela dos intelectuais defendia a volta ao campo, figuras como F. Perroux e J.F. Gravier acreditavam ser possível um processo de modernização que combateria as mazelas da modernidade. Esses autores podem ser classificados como "não-conformistas":

\begin{abstract}
as origens ideológicas e a espiritualidade de Vichy devem ser analisadas com base nos movimentos da juventude de 1930, nesses pequenos grupos que declaravam não pertencer à esquerda nem à direita e insistiam numa mudança interna, na reconstrução da sociedade. Muitos que participavam desses movimentos não conformistas eram agora nomes influentes em Vichy, sobretudo no início, e sempre procuraram fazer prevalecer sua doutrina. Mas o mesmo autor afirma que eles foram buscar na resistência antifascista muitas de suas ideias. Vichy e algumas correntes da Resistência participaram do 'culto a Péguy', por exemplo, e com ele fomentava a 'revolução nacional'. A influência de Charles Maurras e seu nacionalismo místico no governo do marechal era mais visível ainda. $O$ respeito pela autoridade e pela Igreja instituída, o desprezo pelo socialismo, o antissemitismo militante ou latente, muitos temas da Ação Francesa, Vichy os retomava. A ordem moral instituía uma nova atitude puritana, que os escritores não tardavam a assimilar (LOTTMANN, 2009, p. 282-283).
\end{abstract}

Perroux é um exemplo dessa corrente que buscava uma alternativa entre o liberalismo capitalista e o estatismo comunista, defendendo a necessidade da aliança entre burguesia e proletariado a favor da nação (PAXTON, 1972, p. 555-559). Sua postura pró-modernização via no corporativismo um caminho para um sistema novo, em que os patrões unidos aos trabalhadores 
controlam os preços dos serviços e produtos, reforçando o senso histórico das comunidades e sua autonomia (COHEN, 2006, p. 555-569). O Estado seria o elemento capaz de gerir os conflitos sociais, formando um capitalismo dirigido pelo Estado, sendo a região um conjunto de comunidades, que contém as corporações, unidades profissionais locais, que por sua vez coligam as unidades sociais básicas, ou seja, as famílias (COHEN, 2006, p. 569). Tal estrutura lidaria com as comunidades históricas concretas, permitindo o florescimento da real política, a favor da nação, distinta da política fracionária dos partidos políticos (PAXTON, 1972, p. 569). Assim, admitindo o Estado como agente dirigente do desenvolvimento, o planejamento regional e o urbano ganham visibilidade (JACKSON, 2005, p. 161).

O governo de Vichy não partiu do zero para pensar estratégias de planejamento, uma vez que, em 1925, existia um comitê para a gestão da cidade de Pais que, em 1934, publicou o Plano Prost. O documento, promulgado como lei em 1939, organizou o espaço de Paris, estabelecendo um zoneamento de uso, conservação do espaço verde, melhoria das ferrovias, ruas e a construção de rodovias. Além disso, criou uma região parisiense que se desdobra por $35 \mathrm{~km}$ ao redor da catedral de Notre Dame, o que demonstrou uma preocupação para além do tecido urbano (JONES, 2017, p. 431). Porém, de fato, pouco se fez até a década de 1960 devido, por exemplo, à resistência das municipalidades às regras estabelecidas. Contudo, o plano serviu como importante orientação, reforçando opiniões de figuras como R. Dautry, engenheiro que havia modernizado o serviço ferroviário francês e era entusiasta do modelo das cidades-jardins.

Desde a década de 1930, se iniciou uma desindustrialização espontânea de Paris, principalmente de fábricas que se movem para a periferia, fugindo da pressão dos custos imobiliários (JONES, 2017, p. 431-433). Paralelamente, desde o início do século, se consolidou o cinturão vermelho, ou seja, uma aglutinação de cidades e bairros predominantemente operários, suscetíveis à greves e reivindicações populares, que preocupavam a elite social e política da época. Em contrapartida, no seio da cidade, persistiam áreas urbanas degradadas, com habitações improvisadas, cortiços e falta de infraestrutura, algo que deveria ser combatido, portanto, a higiene urbana e o controle da densidade urbana foram objeto das preocupações do Plano Prost.

Diante desses fatos, Vichy cria em 1941 a Délégation Générale à l'Équipement National (DGEN), cujos objetivos eram orientar o processo de desconcentração urbano-industrial, remodelar Paris e planejar o país, sendo que tal órgão mantinha relação com a Fundação Carrel (COUZON, 2003, p. 85). O ordenamento de Paris ficou sob jurisdição do DGEN que usou o Plano Prost como base, conservando sua abordagem regionalista e a intervenção nos quarteirões insalubres. As reformas promovidas pelo barão Haussman são também uma referência, com a consolidação de um boulevard contornando a periferia, seguido de um cinturão verde (WAKEMAN, 2004, p. 130).

Contudo, conforme o regime se degrada, o DGEN fica em uma situação frágil. Próximo do final da guerra, o órgão publica o Tranche de démarrage, cuja palavra de ordem é aumentar a produtividade, importar tecnologias e fortalecer a indústria. O DGEN culpa a falta de indústrias pela derrota na guerra e rechaça posturas liberais, destacando os recursos minerais, o potencial hidroelétrico e a necessidade do Estado de fomentar indústrias (KUISEL; FLORENTIN, 1977, p. 92-96). Recomenda-se ainda o aprimoramento dos recursos humanos, o aumento da produção de alimentos, da energia elétrica e a modernização do sistema de transportes. Com a Liberação e o 
pós-guerra, apesar do Tranche seguir servindo de base para o plano de equipamento nacional de 1946, o Plano Monnet acaba por se sobrepor a essas iniciativas, mesmo que elas possuam pontos em comum (KUISEL; FLORENTIN, 1977, p 97-99). Face à derrota de Vichy, Perroux abandona o corporativismo e se engaja no keynesianismo, mantendo seu prestígio e sua concepção de um capitalismo dirigido pelo Estado assessorado por uma tecnocracia treinada (JACKSON, 2006, p. 157).

Parte dos técnicos de Vichy foi classificada como "mal embarqué, bien arrivé", ou seja, após a queda do regime, não sofreram sanções e continuaram a ocupar cargos públicos. O economista François Perroux, elaborador da teoria de polos de crescimento e Alfred Sauvy, demógrafo e sociólogo, trabalharam na Fundação Carrel e se retrataram quando perceberam a eminente derrota. O mesmo vale para o padre J.-L. Lebret, dominicano que se dedicou ao planejamento regional e trabalhou também no Brasil. Desse modo, como ressalta Lottman (2009, p. 505), o pós-guerra marca uma mudança cultural na França, os cientistas e tecnocratas ganham prestígio social em detrimento dos filósofos e escritores, que ocupam menos espaço no debate público.

Durante o governo provisório, Gravier participa da pasta de aménagement du territoire do Comissariado Geral do Plano (CGP), órgão responsável pelo planejamento, enquanto Perroux funda o Institut de science économique apliquée (ISEA), órgão de formação de quadros técnicos (ADLER, 2005, p. 156-186). Contudo, sua importância é mais abrangente:

\begin{abstract}
Os laços entre o ISEA e o CGP [Comissariado geral do plano] estão de qualquer forma pessoalmente consagrados pelo ingresso de Pierre Uri no Comissariado, onde ele se tornou um dos mais próximos colaboradores de Jean Monnet, mas, de forma mais geral, o CGP, criado em 1946 pelo governo provisório do general De Gaulle sob o impulso de Alfred Sauvy e Jean Monnet, reuniu então várias pessoas fortemente influenciadas por François Perroux e/ou que se encontravam no seu grupo imediato durante a Ocupação, tais como Robert Marjolin e Pierre Uri - Jacques Dumontier, Jean-François Gravier, Jacques-René Rabien ou Jean Vergeot (PAXTON, 1972, p. 586).
\end{abstract}

Segundo Pritchard (2011, p. 312), Gravier também trabalhou da Liberação até 1949 no Ministério da Reconstrução e Urbanismo. No âmbito do CGP sua pasta não obteve resultados significativos entre 1946-47, pois a região estava fortemente associada às ideologias de Vichy (BURNHAM, 2009, p. 29). A ação do Ministério da Reconstrução nesse período foi relativamente restrita, pois a pasta teve que lidar com o déficit habitacional e, em 1946, o Plano Monnet teve pouco interesse na ação regional, pois a prioridade era o reestabelecimento da indústria de base (BURNHAM, 2009, p. 29-30).

Ao final da Segunda Guerra, os líderes da Resistência - incluída parte significativa da esquerda -, e os Gaullistas estão de acordo que a França é um país atrasado do ponto de vista tecnológico, social e econômico, com déficit comercial, aumento da pobreza no campo, carestia e envelhecimento populacional. Urgia, portanto, aumentar o nível de vida, além de renovar tecnicamente a agricultura e a indústria (KUISEL; FLORENTIN, 1977, p 82). Sinteticamente, a pauta da modernização mobiliza as forças de esquerda e direita, criando um terreno fértil para a ação dos não-conformistas da década de 1930.

Além disso, o pós-guerra é mercado pelo surgimento de grupos federalistas que reúnem os não-conformistas. Gravier aderiu ao principal movimento que, não por acaso, aglutinou vários de seus antigos colegas. O Centre d'études institutionelles pour l'organisation de la société 
française, que em 1945 se tornou La Fédération, reúne figuras da Jeune droite, além de outros grupos, e publicou uma revista para difundir suas ideias. No exemplar da La Fédération. Revue de l'ordre vivant de outubro de 1947, encontramos um artigo de Gravier que sintetiza as principais ideias de Paris... que, no mesmo ano, seria publicado na forma de livro pela editora Portulan, cujo proprietário, o industrial Jacques Bassot, integrou o La Fédération (COUZON, 2003, p. 88). No mesmo número, Perroux publica um artigo defendendo a descentralização do Estado e a criação de uma união dos países europeus para proteger a civilização cristã contra os impérios da URSS e dos EUA. Sinteticamente:

\begin{abstract}
O pensamento federalista possui a particularidade de atribuir uma significação inversa aos termos, evocando os recortes territoriais, notadamente 'nação', 'pátria', 'região', 'Estado': ele conjuga de fato um discurso descentralizador fundado sob a organização ascendente da sociedade com a ambição de constituir os vastos reagrupamentos que utilizam as fronteiras a fim de lutar contra o nacionalismo e o imperialismo. Essas são as sobras do mecanismo intelectual singular que favoreceu a reciclagem do arsenal ideológico da revolução personalista e comunitária dos anos 1930 no vibrante apelo pela constituição de uma Europa...comunitária (COUZON, 2003, p. 88).
\end{abstract}

A revista contou com contribuições de Raoul Dautry e o número 34, de 1947, homenageia Georges Sorel, Proudhon e C. Péguy, demonstrando as influências do grupo ${ }^{3}$. Enquanto chefiava o Ministério da Reconstrução, Dautry pediu para que Gravier produzisse um relatório que demonstrasse a importância e pertinência do planejamento territorial. O resultado foi Paris..., que aspirava criticar o Plano Monnet por seu abstracionismo econômico, sem notar que suas ações poderiam reforçar as disparidades regionais. Antes de analisar a principal obra de Gravier, fica clara a sua opção e de seu grupo pela descentralização da administração pública, não obstante é importante ressaltar que disputas entre a centralização e a descentralização político-administrativa na França tem uma longa e controversa história. Michel Phlipponeau (1981) construiu uma síntese sobre o assunto do ponto de vista histórico e geográfico.

\title{
O contexto de Publicação de Paris et le désert français e seu impacto
}

A primeira edição de Paris...contou com o prefácio de R. Dautry e nas suas 414 páginas conserva em parte o estilo de um relatório técnico, sendo ilustrado com cifras, tabelas, gráficos e mapas. Como Marchand (2001) chama a atenção, Gravier frequentemente não referencia as fontes dos dados que utiliza, sejam eles econômicos ou demográficos, fato que observamos também em outros de seus livros (GRAVIER, 1947; GRAVIER, 1953; GRAVIER, 1958). O mesmo se pode dizer das citações, que acompanham aspas, mas na primeira edição de Paris... não estão referenciadas, ou seja, se sabe o autor, mas não a obra efetivamente citada.

Fica evidente, contudo, sua filiação à escola francesa de geografia, pois são comuns às referências a R. Blanchard, G. Chabot, A. Cholley, E. de Martonne, P. George, sendo A. Demangeon um dos autores mais citados, em função de sua geografia econômica e pela ideia de "congestão cerebral" parisiense extraída de seu Paris, la ville et sa banlieu, de 1934 (GRAVIER,

3 Os sumários da revista podem ser acessados no repositório da União Europeia: <https://archives.eui.eu/en/fonds/100593?item=AMG\%2FDOC-23>, acesso em 19 de jan. de 2020. 
1947). Demangeon culpa a concentração da administração monárquica em Paris pelo início da apoplexia urbana (COUZON, 1997. p. 18).

Quadro 1. Comparação dos sumários das edições de Paris et le désert français.

\begin{tabular}{|l|l|}
\hline Edição de 1947 & Edição 1958 \\
\hline Balanço & I. O sistema \\
\hline 1. Ponto de partida & II. A era do carvão na França \\
\hline $\begin{array}{l}\text { 2. Dois terços da França morrem } \\
\text { lentamente }\end{array}$ & III. A era neotécnica no mundo \\
\hline 3. Migrações internas & $\begin{array}{l}\text { IV. Devotos de uma revolução } \\
\text { francesa }\end{array}$ \\
\hline 4. Paris despovoa a França & $\begin{array}{l}\text { V. Reformas das estruturas: da } \\
\text { comuna à nação }\end{array}$ \\
\hline 5rincípios e métodos \\
\hline 1. Investir ou consumir
\end{tabular}


Segundo o próprio Gravier (1953), a primeira edição de Paris... e do livro Mise en valeur de la France, de 1949, se esgotaram rapidamente, o que instigou o autor e os editores a lançarem o livro Décentralisation et progrès technique, mesclando ideias dos dois títulos. Apesar de livros diferentes, as três obras arroladas, bem como a segunda edição de Paris..., defendem as mesmas interpretações, sendo todos ricamente ilustrados com gráficos e mapas, mas possuindo a dubiedade no tocante às fontes. Em 1958, a Flammarion compra os direitos de Paris... e publica uma segunda edição. O Quadro 1 compara as duas edições, lembrando que existe uma terceira edição, de 1972, que não conseguimos localizar. Mesmo que as hipóteses e as interpretações sejam similares, se nota uma estratégia argumentativa diferente. Enquanto a primeira edição se divide em uma primeira parte que discute os problemas da França, seguida de uma outra dedicada a um programa de ação, a segunda edição mescla os dois aspectos.

Apesar de termos estratégias expositivas distintas comparando a primeira e a segunda edição, nota-se que os argumentos do autor são semelhantes. A análise que fizemos das duas edições de Paris..., e dos livros Mise em valeur de la France e Décentralisation et progrès technique revelam uma unidade argumentativa explícita, o que nos levou a agrupar tais obras em um bloco de investigação. Sendo assim, o critério adotado de seleção analítica das obras foi de um lado sua unidade argumentativa, de outro, o lapso temporal de suas publicações (1947-1958) que se encaixam em um contexto social de valorização do planejamento regional que culmina, não sem oscilações e revezes, na criação do DATAR em 1963.

Em todas essas obras, a abordagem de Gravier é regional e, como sintetizou Couzon (1997, p. 14-15), cada unidade deve ser conhecida segundo suas comunidades de trabalho e especializações econômicas, seguidas de suas redes internas de ligações, com a identificação de centros e metrópoles regionais. Logo após estes procedimentos, é preciso estipular planos para a exploração de suas potencialidades e/ou para o descongestionamento industrial; e, por fim, elaborar ações para a recuperação rural das regiões.

Tal enfoque aparece também na segunda edição de Paris..., de 1958, que é mais sucinta - com apenas 318 páginas -, possuindo um estilo acessível para leigos. Destaca-se o acréscimo das ideias de Patrick Geddes e Lewis Mumford, referências já utilizadas em Décentralisation... de 1953. Como parte da repercussão da obra, Gravier ganhou o prêmio Gobert da Academia Francesa, em 1959, e viu sua obra inspirar um documentário homônimo a Paris... ${ }^{4}$ em 1957. Ao analisarmos as duas edições de Paris... e Décentralisation..., acreditamos que seja possível extrair ideias que são defendidas a longo prazo sob diferentes argumentos. Sinteticamente (GRAVIER, 1947; GRAVIER, 1953; GRAVIER, 1958), pode-se dizer que:

a) Gravier incorpora a teoria de Alfred Sauvy e de seu grupo, que admite um ciclo de retração demográfica iniciado após a Revolução Francesa e que se estende até 1930. Tal período seria marcado pela hegemonia da burguesia e pela institucionalização de uma ética malthusiana, individualista, em que a ascensão social está condicionada à acumulação econômica (ADLER, 2005, p. 185). A lógica da distinção social pelo dinheiro, que substitui o direito nobiliário, contrai a taxa de natalidade, assim como a emancipação feminina. Tal situação, frente à industrialização,

\footnotetext{
4 Sob direção de Roger Leenhardt e Sydney Jezequel. Disponível em <https://www.dailymotion.com/video/xn5dj9>, acessado em 12 de dez. de 2019.
} 
significa êxodo rural, desabastecimento alimentar, importação de gêneros de primeira necessidade e recursos rurais ociosos. Em contrapartida, a taxa de mortalidade na França diminui lentamente, em parte devido à falta de modernização do território e ao alcoolismo, segundo o autor. Gravier (1947, p. 81-89) diz que enquanto outros países europeus tiveram um explosivo crescimento demográfico durante o século XIX, a França teve um avanço tímido e retração no início do século XX. O demógrafo Le Bras (2007, p. 158), entretanto, classifica a obra de Gravier como um panfleto natalista, cujas análises demográficas usam sempre as mesmas fontes, abordadas de maneira simplista e com um viés ideológico.

Segundo Gravier, "Sauvy exprimiu os resultados de estudos numerosos e eruditos de demografia comparada em uma fórmula que os homens de Estado deveriam sempre manter presente no espírito: 'As grandes cidades são as tumbas da raça'” (GRAVIER, 1953, p. 116), o que ilustra seu pessimismo no tocante às cidades. Paralelamente, se admite que as crises econômicas, o desemprego, a falta de acesso à terra é o que provoca o inchamento das cidades, dissolvendo as comunidades (GRAVIER, 1953, p. 162).

Segundo nosso autor, a França deveria expandir sua população para cerca de 70 milhões de habitantes (GRAVIER, 1947) ${ }^{5}$, sendo que o déficit populacional em comparação ao vizinhos teria sido um dos elementos que facilitaram o início das guerras mundiais e a instabilidade europeia. Sua obra possui um raciocínio geopolítico subjacente, pois uma grande população possibilita maior poder militar e econômico, ideia incorporada pelo general De Gaulle, fomentando uma política pública de expansão da população (ADLER, 2005, p. 184). Gravier é taxativo ao afirmar que a França é um país cujo interior é pouco povoado, o que afeta a proteção das fronteiras, tendo em vista o equilíbrio com os vizinhos (GRAVIER, 1953, p. 22-23). Surge aí a colonização interna, tema discutido face ao início do processo de independência de várias colônias.

b) A expansão demográfica francesa envolveria também uma política de migração, principalmente de homens solteiros de determinadas nacionalidades, que deveriam ser rapidamente assimilados à cultura francesa. Como ressalta Adler (2003, p. 181-183), o plano migratório Gravier se baseia também nos estudos do grupo de Sauvy, que nem sempre vê a chegada de estrangeiros como um fator positivo. Os migrantes seriam inseridos em um contexto de rápida assimilação, interessantes apenas para ocupação de postos de trabalho simples.

c) O crescimento exacerbado de Paris, em sua gênese, se relaciona com a política. Luís XIV foi o primeiro agente político centralizador, porém, tinha como justificativa a experiência da Fronda ${ }^{6}$. Para Gravier, a reação de um poder político ameaçado é a centralização. Na sequência histórica, apesar de durante a Revolução Francesa existirem tendências descentralizadoras e federalistas, elas não se impuseram como forças hegemônicas, pois Napoleão inicia uma tradição de centralização que canaliza a força política e econômica em Paris (GRAVIER, 1947, p. 112-123).

d) Assim como os demais geógrafos vidalianos, Gravier compara a nação a um organismo vivo, cujas partes são ligadas pelas redes de estradas e formada pelas regiões, que têm existência própria, mas exercem determinadas funções no conjunto nacional. Em 1947, ele já identifica que

\footnotetext{
${ }^{5}$ Segundo Jones (2017, p. 462), a França em 1946 tem 41 milhões de habitantes, em 1966, cerca de 50 milhões e, em 1999, 60 milhões.

${ }^{6}$ Uma série de guerras civis ocorridas na França entre 1648 e 1653.
} 
cada região é comandada por uma cidade e utiliza a presença de comércios e serviços como critério de uma hierarquia urbana - raciocínio semelhante ao de Walter Christaller (GRAVIER, 1953, p. 165).

e) Paris, como centro da nação, cria uma realidade distorcida: ela é equipada de infraestrutura, enquanto sua periferia e as províncias estão desprovidas de serviços essenciais como eletrificação, água potável e habitações salubres. Observa-se então a dissolução da família, o desenraizamento dos camponeses, o aumento do alcoolismo, dentre outros problemas sociais. Assim, o déficit habitacional deve ser combatido pelo planejamento, com a oferta de moradia digna nas províncias e na região parisiense. No pós-guerra, o déficit era significativo e, inclusive, era uma política governamental complementar ao planejamento regional, contudo, era também seu concorrente, pois a construção de casas era mais urgente do que investir em benefícios para empresas se mudarem para o interior (COUZON, 1997, p. 15).

f) Gravier, em várias obras, lança mão do método comparativo, contrapondo a situação geográfica dos países europeus. Logo no início da primeira edição de Paris..., ele compara população, produção de carvão e de máquinas entre Inglaterra, Alemanha e França (GRAVIER, 1947, p. 1040) e, em outra obra, compara as experiências de planejamento regional dos países europeus (GRAVIER, 1953). Ao identificar os pontos de estrangulamento do desenvolvimento francês, o autor é taxativo em recomendar a expansão da capacidade energética, bem como da quantidade e da qualidade da mão de obra. Para Gravier, ter um plano é fundamental tanto quanto a vitória militar, pois a França teria, entre 1929 e 1945, perdido 3 dos seus 15 milhões de produtores para atividades que ele denomina parasitárias (terciário não-produtivo, ou seja, comércio e serviço público) (GRAVIER, 1947, p. 215). Nesse sentido, os EUA são apontados como a nação mais eficiente e produtiva do mundo e, portanto, um exemplo a ser seguido (GRAVIER, 1953, p. 187).

O autor (GRAVIER, 1953, p. 210-211) elogia a Tennessee Valley Authority (TVA) e seu uso múltiplo da bacia hidrográfica (irrigação, geração hidroelétrica e transporte) como medida que favorece a região como um todo. Isso nos leva a afirmar que ele adota uma concepção de planejamento integral que pode ser também encontrada na obra de Perroux e geógrafos como $P$. George, ou seja, planejamento nacional, regional e urbano devem ser concebidos em conjunto.

g) Devido ao seu gigantismo, Paris acaba ganhando mais subsídios governamentais do que outras regiões do país. Além disso, os altos salários em comparação à província impulsionam o êxodo rural, resultando na inflação que prejudica a economia nacional. Ademais, se formam os trustes, como Gravier (1947, p. 131-185) classifica: a maioria dos bancos e instituições financeiras está em Paris, bem como as sedes de indústrias, empresas comerciais e, por fim, as grandes escolas e universidades. Apesar de Gravier identificar a existência de complexos industriais empresas que estabelecem integração no processo produtivo -, como nota Marchand (2001), ele não reconhece nenhum fator positivo advindo da concentração urbano-industrial, como, por exemplo, economias de escala ou de aglomeração, onde a concentração de empresas provocaria uma redução de custos e um maior número de inovações produtivas, para citar alguns elementos.

Inclusive, ele associa as construções insalubres e a cidade poluída, mal ordenada e sem espaços verdes à lógica liberal e à burguesia malthusiana regida pela lucratividade e não pelo bem-estar da comunidade. Nas palavras do autor: "O mais verdadeiro é que esses países [europeus e os EUA], notadamente na sequência da 'grande crise' e a favor da economia de 
guerra, romperam com o capitalismo liberal que havia instaurado a moral materialista e malthusiana" (GRAVIER, 1953, p. 240), ou seja, o dirigismo estatal é resultado da evolução histórica do Estado.

h) Gravier não se esquiva da discussão de aspectos arquiteturais, indicando o que acredita ser o melhor tipo de hábitat para cidade. Ele elogia moradias pouco densas, próximas à espaços verdes com no máximo três andares, indicadas como modelo, bem como as cidades-jardins. Trata-se de eleger qual será o modelo de habitação do período neo-técnico (GRAVIER, 1953, p. 245), preocupação que remete a P. Geddes.

i) O antídoto para a situação francesa é a desconcentração industrial e também a administrativa, com a dispersão de serviços públicos e infraestruturas no território francês. Paralelamente, a preocupação de Gravier não é só com a indústria, o mundo rural tem um peso nessa equação, pois a França seria um dos países mais férteis e com maior área agricultável de toda Europa. Sob sua perspectiva, as regiões devem ser concebidas como unidades administrativas autônomas, através do sistema federativo, e autárquicas, ou seja, capazes de se inserirem no conjunto nacional de maneira funcional. O resultado seria a atenuação da distinção entre campo e cidade, com a instalação de indústrias em áreas rurais, sendo que o desemprego tecnológico no campo não expulsaria os trabalhadores, mas os fixaria, possibilitando o desempenho de atividades complementares nas fábricas ou no artesanato. A longo prazo, se formariam nebulosas de cidades e campos integrados (GRAVIER, 1947; GRAVIER, 1949; GRAVIER, 1953, p. 84). Assim, não é exagero afirmar que Gravier possui um inconsciente anarquista, uma vez que suas concepções se assemelham às proposições de $P$. Kropotkin, mesmo que ele não o cite.

\section{O inconsciente progressista de um autor conservador}

Como nos ensina Berdoulay (2003, p. 52) ao expor sua abordagem contextualista e ao lidar com o tema das influências intelectuais, deve-se buscar as razões ou demandas concretas para o uso de determinadas ideias. Nesse sentido, claramente Gravier cita o discípulo de Kropotkin, P. Geddes, mas denota um desprezo pelo anarquista russo. Contudo, não é possível negar a similaridade dos argumentos e das interpretações de Kropotkin e Gravier e, nesse sentido, o método indicado por Berdoulay permite vislumbrar que para o conservador Gravier seria possivelmente embaraçoso se remeter a um anarquista radical. Em contrapartida, Kropotkin foi um dos defensores pioneiros da economia local, da descentralização industrial e fez propostas práticas para a diminuição da divisão entre campo e cidade, ou seja, suas conclusões são importantes para alguém que pretende criticar a organização espacial oriunda do processo capitalista de modernização industrial e urbana. Muitas de suas concepções, talvez um tanto atenuadas quanto ao seu posicionamento político, foram transmitidas a P. Geddes, uma figura mais moderada, sendo esse autor basilar para o reforçamento dos argumentos de Gravier sobre sua tese acerca da ação nociva de Paris.

Kropotkin (1985) em seu Fields, Factories and Workshops defende a autonomia local, ou seja, que as regiões e cidades sejam capazes de produzir todo o necessário para sua subsistência, demonstrando as desvantagens do comércio internacional, segundo sua opinião 
mais caro devido ao transporte. Chama a atenção principalmente a semelhança entre as posições mais gerais de Gravier (1947) e do anarco-federalista P. Kropotkin (1985) sobre o campo: ambos concordam que melhorias contínuas devam ser realizadas para que ele seja fonte de recursos e alimentos. Os tempos de pousio ou o inverno liberam os camponeses para a indústria ou para 0 artesanato e os avanços técnicos do início do século XX, notadamente a eletricidade e a melhoria dos transportes, permitiriam que as populações rurais superassem o isolamento geográfico.

Para Kropotkin (1985, p. 27) é preciso superar a dicotomia entre o trabalho manual e intelectual, do conhecimento científico e do técnico/artesanal, bem como a cisão campo-cidade, possibilitando a dissolução da alienação do trabalhador, fomentando uma união harmoniosa entre capital e trabalho. Parte das economias exportadoras produziria pobreza, por exemplo, ao empregar fazendas para o plantio e exportação de café, enquanto a disponibilização de alimentos e o acesso à terra ficam em segundo plano (KROPOTKIN, 1985, p. 40).

Privilegiando pequenas propriedades, adaptação das espécies agrícolas, exploração mecanizada e intensiva, Kropotkin aspira mais produção com menos trabalho. Como exemplo, o russo comenta as culturas dos jardins da periferia de Paris que abastecem a cidade com técnicas agrícolas eficientes, utilizando-se de cercas verdes para proteção dos cultivos (KROPOTKIN, 1985, p. 68-76).

Além disso, apesar de terem visões políticas opostas, Gravier e Kropotkin compartilham a repulsa pela teoria de Malthus e seus efeitos psicológicos:

\begin{abstract}
Resumidamente, pode-se dizer que a teoria de Malthus, transformada em uma fórmula pseudo-científica pelo desejo secreto das classes possuidoras de riqueza, se torna o fundamento de todo um sistema de filosofia prática, que permeia ambas mentes, educadas e não-educadas, e reage, como filosofia prática (sempre o faz) sob a filosofia teórica de nosso século (KROPOTKIN, 1985, p. 78-79).
\end{abstract}

Matlhus não considera os avanços técnicos capazes de aumentar a produtividade da indústria e da agricultura. A solução para o desemprego seria o acesso a terra e os pequenos negócios artesanais, que podem estancar o abandono dos campos e a miséria. Aliás, as pequenas propriedades mercantis são a chave para o surgimento de grandes negócios (KROPOTKIN, 1985, p. 131-138). Outrossim, Kropotkin (1985, p. 154) chama atenção para a descoberta das hidroelétricas que possibilitariam a desconcentração industrial, barateando sua localização longe dos grandes centros. Para o anarquista, a grande indústria não elimina o artesanato e as pequenas oficinas, que continuam empregadas em tarefas que não podem ser mecanizadas - reparos, pinturas manuais, trabalhos delicados, etc. Além disso, as grandes indústrias estariam mais preocupadas com o controle do mercado por meio de monopólios, do que com o aumento da produtividade, pois a atualização de seu maquinário seria onerosa, ao contrário das pequenas fábricas que podem se renovar mais facilmente, obtendo maior produtividade e menor preço (KROPOTKIN, 1985, p. 154).

Encontramos ainda um elemento importante compartilhado por Kropotkin e Geddes, que de certa forma reverbera no pensamento de Gravier. O anarquista e seu discípulo têm uma visão positiva da cidade medieval europeia, uma vez que ela consolida a reafirmação da autonomia dos burgos em relação aos senhores feudais. As cidades que organizavam milícias de cidadãos gozavam de autonomia também perante ao rei e suas eventuais tentativas de centralização do poder. O resultado desse processo é a possibilidade de uma participação mais democrática dos 
citadinos, sendo que a ascendente burguesia foi capaz de construir uma cidade que fizesse jus à sua prosperidade, embelezando-a com catedrais e outros espaços públicos. Nesse sentido, ambos elogiam as tradições do medievo e do Renascimento, baseadas em espaços verdes e bem ventilados, com a construção de moradias relativamente boas, bem como uma lógica que visa o espaço urbano como patrimônio da cidade, contrapondo-se ao utilitarismo que vigora a partir da revolução industrial (GEDDES, 1915, p. 10). Como vimos, Gravier, Perroux, Sauvy, dentre outros não-conformistas, se inspiram no período medieval, como a releitura das corporações, por exemplo.

Apesar das similitudes, em nenhuma das obras de Gravier, Kropotkin é analisado profundamente, ao contrário de P. Geddes. A partir do início da década de 1950, Gravier utiliza as ideias de Geddes, notadamente a periodização delineada entre as eras paleotécnica e neotécnica. Apesar de ter recebido alguns comentários na prestigiosa revista Annales de géographie (fundada por Vidal de la Blache), Geddes estava longe de ser um referência central para a escola francesa de geografia e, paralelamente, Kropotkin era conhecido na França mais como ativista anarquista, do que como cientista/geógrafo. Outro possível vetor de contato com Geddes, no caso de Gravier, foram os intercâmbios entre França e EUA no pós-guerra. Isso explicaria sua citação a Lewis Mumford, um dos mais ferrenhos defensores das ideias de Kropotkin, uma vez que, na década de 1940, a experiência da TVA, inspirada nas ideias de Geddes, foi propagandeada e recebeu visita de Claudius-Petit, chefe do Ministério da Reconstrução. De toda forma, Gravier encontrou em Geddes conceitos que reforçam o poder explicativo das interpretações realizadas na década de 1940, sobre a situação geográfica francesa.

Basicamente, Geddes defende que o período paleotécnico se inicia com a revolução industrial e se estende até fins do século XIX, remetendo ao domínio tecnológico do carvão e às inovações técnicas que decorreram de seu uso. A exploração dessa matéria prima, de difícil extração e transporte, teria fomentado a construção de ferrovias e reforçado uma topologia concentrada. A cidade industrial cresce caoticamente formando conurbações, sedenta por trabalhadores que não encontram condições de habitação adequadas (GEDDES, 1915, p. 37; GRAVIER, 1953, p. 7-10). O predomínio do carvão explicaria o atraso francês, que possui reservas relativamente pequenas se comparadas com as da Inglaterra e da Alemanha.

Contudo, esse panorama se transforma com a chegada da era neotécnica consolidada inicialmente entre 1875 e 1900 e marcada pela diversificação das fontes energéticas, com as usinas hidroelétricas, o uso do petróleo - mais fácil de transportar que o carvão - e, finalmente, a energia nuclear. Estas novas matrizes permitiriam uma dispersão da indústria no território, inclusive possibilitando que a pequena indústria se tornasse competitiva (GRAVIER, 1953, p. 11). Além disso, temos avanços nos meios de comunicação (rádio, telefone, televisão, etc.) e nos meios de transporte com o carro e o caminhão, que diminuem drasticamente o isolamento rural. $A$ revolução neotécnica possibilita ainda o surgimento de novas matérias primas como plásticos, 0 alumínio, derivados petroquímicos e o uso de fertilizantes agrícolas (GRAVIER, 1953, p. 11).

Geddes (1915, p. 29-36) associa o período paleotécnico a uma mentalidade concorrencial, orientada pelo frenesi da acumulação capitalista, enquanto o período neotécnico abre espaço para a cooperação, reforçada por uma sociedade mais educada, pelo despertar da consciência de cidadania e por uma ideia de que a cidade é patrimônio coletivo. Assim, a mudança técnico-científica possibilita uma transformação psicológica e da geografia social, 
implicando no desenvolvimento da saúde coletiva, do bem-estar e do embelezamento urbano (GEDDES, 1915, p. 129). Geddes incorpora assim a teoria do apoio mútuo de Kropotkin, defendendo a cooperação como elemento chave da evolução urbana e social, utilizando a educação como ferramenta de emancipação social. O inverso dessa possibilidade evolutiva seria a kakotopia, uma situação de gigantesca riqueza monetária, mas com esgotamento dos recursos físicos, humanos, dissipando a vida física e gerando favelas. Constitui-se então um meio geográfico que não é solidário, mas perverso, causador da deterioração física e cultural do ser humano (GEDDES, 1915, p. 74).

Ao associar os problemas sociais à forma social de exploração do trabalho, Geddes vai na contramão da mentalidade de sua época: culpar a cidade pelos males do mundo e criar uma visão pessimista da urbe, concepção que remonta à queda bíblica da Babilônia. Kropotkin, Reclus e Geddes, dão lugar a uma visão mais realista, ponderando as vantagens e as desvantagens do desenvolvimento urbano do fin de siècle, sob o norte da máxima de que cada evolução, gera um grau de retrocesso. Como vimos, no entanto, Gravier de maneira distinta vê as grandes cidades sob um viés pessimista.

Para Geddes, as cidades devem ser pensadas conjuntamente com as regiões, sendo planejadas, não por um tecnocrata todo poderoso, mas por meio do estudo de sua constituição pregressa e presente, bem como da educação cívica da população, que envolve observação do meio vivente, além de trabalhos de campo (GEDDES, 1915). A cidade neotécnica não crescerá mais como uma mancha de óleo, mas como uma estrela, cujas pontas flanqueiam áreas verdes e rurais. A mudança de indústrias pesadas das cidades para locais adequados, além do melhoramento da poluição do ar, abre espaço para parques e pequenas oficinas (GEDDES, 1915, p. 97-105). O planejamento de Geddes, contudo, não se impõe como modelo, na medida em que cada região possui sua individualidade (GEDDES, 1915, p. 157).

\section{Ascensão e queda das propostas de J.-F. Gravier}

O espaço institucional de Gravier no pós-guerra se relaciona com o convite feito por R. Dautry, que ocupava o Ministério da Reconstrução e do urbanismo. Em 1946, Dautry é demitido, porém, a frente da pasta ele criou uma diretoria de habitação e planejamento urbano e outra para o planejamento territorial (aménagement $d u$ territoire) com uma unidade dedicada à desconcentração industrial, envolvendo Gravier (BURNHAM, 2009, p. 28). Mesmo que Gravier participasse também do Comissariat Général du Plan (CGP), o Plano Monnet não deu demasiada atenção ao planejamento regional e a urgência em resolver o déficit habitacional acabou por colocar o urbanismo em primeiro plano. É após a publicação de Paris... que o tema do planejamento regional ganha repercussão (BURNHAM, 2009, p. 30).

Segundo Couzon (1997, p. 18), entre 1946 e 1947, Gravier trabalhou com Pierre Gibel em um órgão de planificação da região parisiense, uma vez que o sucessor de Dautry dá fim ao setor de descentralização. Entretanto, as ideias de Gravier e a agenda de desconcentração ganham força devido à ação de Eugène Claudius-Petit, um dos principais líderes da Resistência, representante do movimento Franc-tireur, deputado pela União democrática socialista da 
Resistência e Ministro da Reconstrução entre 1948 e 1956. Amigo de Le Corbusier e interessado no planejamento ainda no início da década de 1940, Claudius-Petit lê trechos do livro de Gravier na Assembléia Nacional no intuito de dissuadir seus colegas contrários ao planejamento regional (BURNHAM, 2009, p. 30). A gestão de Claudius-Petit é marcada pela revisão do Plano Prost, mantendo vários de seus princípios, como a necessidade de intervenção em áreas insalubres e promovendo levantamentos de dados realizados pelo grupo Economia e Humanismo?. Paralelamente:

\begin{abstract}
A difusão de Paris et le désert français se efetua devido aos antigos colegas do autor no Ministério da Reconstrução e Urbanismo, e notadamente, a Claudius-Petit, então deputado. Em 1953, Claudius-Petit publica um artigo intitulado 'Espírito do Planejamento do Território' na revista Economie et Humanisme em que ele homenageia Jean-François Gravier e Le Corbusier por suas conclusões similares, apesar de suas diferenças sobre 'o mal de nosso século', em que eles se levantam contra a cidade tentacular, a cidade que vai sempre atrair para si mais habitantes, porque ela os fornece sempre mais trabalho (COUZON, 1997, p. 19).
\end{abstract}

O resultado de suas ações é a criação da Direction de l'aménagement du territoire (DAT) e seus respectivos fundos de financiamento. Apesar de incorporar integralmente as teses de Gravier, Claudius-Petit também se atenta para a situação de Paris, que deve ser modernizada. As experiências de desconcentração alcançadas em sua gestão foram poucas, mas emblemáticas, envolvendo empresas como Gillete, Kodak, Renault, dentre outras (POUVREAU, 2003, p. 48). Segundo Pouvreau (2003, p. 51), ao deixar o Ministério em 1952, a política de Claudius-Petit para a construção de habitações era bem aceita, mas a de planejamento estava sob risco, em função dos interesses de empresários e políticos.

De acordo com Burnham (2009, p. 30-34), os órgãos de planejamento regional enfrentavam problemas do ponto de vista da administração pública: (1) a eleição de primeiros ministros liberais implicava na falta de verbas, como foi o caso da ascensão de Antoine Pinay entre 1952 e 1953; e (2) como o planejamento regional implica ações multisetoriais (construção de rodovias, eletrificação rural, etc.), ele enfrentava resistência de outros ministérios que tinham sua esfera de ação invadida. Assim, parte dos políticos e da burocracia resistem à consolidação de uma política regional, mas, em 1954, os políticos da Bretanha apresentam um plano independente de desenvolvimento regional, o que alerta os demais governantes (BURNHAM, 2009, p. 183).

Após um época de retração, o planejamento regional entraria na ordem do dia nos governos de Pierre Mèndes-France (1954-1955) e Edgar Faure (1955-1956) e, não por acaso, no mesmo período é publicada a segunda edição de Paris... (1958). Face às dificuldades anteriormente enfrentadas, um grupo de políticos e tecnocratas organizou um número especial da Revue Française de Science politique (ano 6, $n^{\circ} 2$, de 1956) com um dossiê sobre o "planejamento do território, problemas políticos e administrativos". O número, que inclui um artigo de Gravier, propõe uma reforma da administração pública para o planejamento regional, possibilitando a criação de missões com objetivos específicos, o que extinguiria as resistências dos ministérios (BURNHAM, 2009, p. 33-34).

Mesmo com a simpatia do primeiro ministro socialista Guy Mollet (1956-1957), a proposta emperrou devido à geração de empregos e à construção de moradias baratas, mesmo que o DAT

\footnotetext{
7 Grupo fundado, em 1941, pelo padre Louis-Joseph Lebret, François Perroux, Gustave Thibon, dentre outros. Baseados na doutrina cristã e em reflexões sobre economia política, o grupo aspira propor um sistema econômico mais justo e humano.
} 
tenha realizado um levantamento das áreas viáveis para investimentos (BURNHAM, 2009, p. 34). É somente na V República, durante o governo de George Pompidou (1962-1968) que a proposta avança. Utilizando-se do discurso do atraso francês, da necessidade de colonização interna, da construção de infraestruturas e do fortalecimento das indústrias, Pompidou cria um novo órgão, chamado DATAR. O órgão, criado em 1963, mantém um caráter interministerial, com recursos garantidos para seus projetos, ancoragem legislativa e com presença em comissões e secretarias que lidam com questões territoriais, notadamente o Comité interministériel d'aménagement et de développement du territoire (CIAT), instituído em 1960. A criação do DATAR finda o dualismo existente entre os planos de quatro anos do CGP e os planos de longo prazo do Ministério da Construção (BURNHAM, 2009, p. 40). O órgão herda o conceito de metrópoles de equilíbrio e cuida de sua operacionalização (MURARD; FOURQUET, 2004, p. 236-237), porém o choque do petróleo, em 1973, inibe gastos do governo com o planejamento regional.

Se a partir da década de 1960 o planejamento regional se desenvolve, a temática da desconcentração sofre um revés, pois é estabelecido o distrito da região da Grande Paris, em 1960, e se aprova o Plan d'aménagement et d'organisation générale de la région parisienne (PADOG), que rompe com as ideias de Gravier (MURARD; FOURQUET, 2004, p. 21). O grupo que elabora o plano opta por uma desconcentração concentrada se valendo de projeções demográficas que indicam o crescimento substancial da região parisiense até o ano 2000. Com a gestão de P. Sudreau (1958-1962) no Ministério da Construção, os urbanistas são substituídos por engenheiros (COUZON, 1997, p. 20), que inspirados na experiência inglesa, planejam infraestruturas de transporte e cidades-satélite ao redor de Paris, ao longo das linhas de trem, respeitando-se o cinturão verde na periferia imediata à metrópole, sem isolar as novas cidades (MURARD; FOURQUET, 2004).

As cinco novas cidades distam no máximo 50 quilômetros de Paris, possuindo entre 350 e 500 mil habitantes e se pretendem como novas centralidades que substituiriam em parte Paris. A estimativa de que Paris teria 14 milhões de habitantes no ano 2000, a escassez de moradias e infraestruturas pesaram na aprovação do projeto. Destaca-se que a periferia foi reelaborada seguindo o urbanismo e a arquitetura moderna de Le Corbusier (MURARD; FOURQUET, 2004).

\section{Considerações finais}

Tendo em vista a trajetória de Gravier, o contexto de sua obra, seus fundamentos e influências, suas redes sócio-profissionais e as consequências de sua obra, como poderíamos explicar seu sucesso? Apesar de conservador, Gravier foi capaz de superar o legado de Vichy ao destacar o fenômeno das desigualdades regionais, demonstrando que era impossível a inércia diante delas, uma vez que se colocava em risco a unidade nacional. Seu diagnóstico, além de agradar as elites regionais, se mostrou um fato evidente diante da geografia e da história francesa. Mesmo que a obra de Gravier possua fragilidades científicas, seu argumento concedeu prestígio e força política ao campo do planejamento regional, sendo só questionado nos anos 1960, como demonstram Murard e Fourquet (2004, p. 8-30). 
Não obstante suas opções políticas, Gravier acabou consciente ou inconscientemente reproduzindo ideias progressistas de P. Geddes e P. Kropotkin. Nota-se que essas ideias não explicam apenas as tendências do início do século $X X$, pois a hegemonia atual do paradigma produtivo do toyotismo reforça a desconcentração produtiva, com empresas estabelecendo pequenas fábricas dispersas nos territórios dos países, desmanchando as linhas de produção e fomentando trabalhadores polivalentes dentro das fábricas. Infelizmente, ao invés da emancipação, esse modelo reforça a exploração dos empregados e fragiliza seus direitos.

Apesar dessas tendências, as concentrações urbanas persistem. Em 2008, a Ilê-deFrance, onde se localiza Paris, que correspondia a $2 \%$ do território francês, concentrava $19 \%$ de sua população e possuía uma produção que englobava $29 \%$ do Produto interno bruto francês (LAFOURCADE, 2012, p. 7-13). Os pessimistas diriam que o planejamento falhou em seu objetivo, os otimistas argumentam que sem planificação as estatísticas demonstrariam ainda mais concentração.

Explica-se o sucesso de Gravier também pela adaptação da proposição da desconcentração para a situação francesa, num contexto em que essa medida era bem aceita internacionalmente. Assim, no caso francês, ela teria sido aplicada tardiamente: os EUA com a experiência da TVA empregavam a descentralização e o planejamento regional desde a década de 1930; o mesmo ocorrera na URSS desde a década de 1920; e, na Inglaterra, desde o início da década de 1940. Sendo assim, Gravier agiu como um "tradutor" do conceito para a realidade francesa.

Dessa forma, a desconcentração teve um amplo escopo de orientações políticas, lidando com as economias de aglomeração que gravitam em torno das cidades; ou seja, de um lado, temos cidades modernas, de economia pujante, de outro, espaços relegados ao atraso. Novamente, sobressai o paralelo entre Gravier e Perroux, que, no pós-guerra, adere ao keynesianismo quando este era consenso dentre os dirigentes das principais potências do mundo, engajamento que permitiu a reconfiguração de suas ideias e, ao mesmo tempo, a ampliação de seu capital cultural. Mesmo que Gravier não possua a mesma envergadura de Perroux, observase a mesma estratégia, sendo que a desconcentração urbano-industrial permitiu ampliar seu capital cultural no campo científico da geografia e junto ao planejamento regional. Jean Labasse, Michel Rochefort, Pierre George, Maurice Le Lannou e M. Phlipponeau, grosso modo, se engajaram no consenso pela valorização do planejamento regional e pela desconcentração. Mesmo que sua obra não seja debatida aprofundadamente, Gravier e Paris... são uma citação frequente, evocado a simples constatação que Paris é uma grande cidade e o interior francês é pouco desenvolvido. Em suma, ele apresenta uma agenda para o desenvolvimento francês que é aceita pelos acadêmicos e pela elite política francesa.

O discurso de Gravier corroborou com a disposição de modernização da economia e do território francês, o que se traduziu na criação de órgãos de planejamento regional e no desenvolvimento de estratégias como as metrópoles de equilíbrio - centros regionais que foram equipados com infraestruturas e serviços sofisticados - e o desenvolvimento de cidades médias. Tais estratégias chegaram ao Brasil em meados do século XX e tiveram importante repercussão, reproduzindo o consenso de que a concentração urbano-industrial é nociva ao desenvolvimento brasileiro, pois reforça as desigualdades regionais. O engenheiro Lucas Lopes conhecia a obra de Gravier (DINIZ, 2008) e o padre Lebret ao estudar Pernambuco indica centros regionais a serem 
estimulados, revertendo a concentração de Recife (CHIQUITO, 2013). Finalmente, Michel Rochefort que trabalhou no IBGE e que, assim como Lebret, influenciou figuras chave do planejamento regional e da geografia brasileira era partidário da desconcentração, fato evidenciado pela proposição das metrópoles de equilíbrio, apresentada em estudo desenvolvido com Jean Hautreux ao governo francês no ano de 1963, concomitante a um período de intenso trânsito no Brasil (BOMFIM, 2015). Por fim, Gravier é personagem relevante e controversa para compreensão da história do planejamento regional francês e, apesar de nunca ter sido traduzido para o português, tem suas principais obras depositadas em bibliotecas de importantes instituições brasileiras ${ }^{8}$.

Trabalho financiado pela Fundação Araucária.

Submetido em 19 de março de 2020.

Aceito para publicação em 9 de setembro de 2020.

\footnotetext{
${ }^{8}$ Por meio dos catálogos digitais encontramos as obras de Gravier nas bibliotecas das seguintes instituições: Câmara dos Deputados Federais, Senado, Itamaraty, Escola Superior de Guerra, Universidade Federal do Rio Grande do Sul, Universidade Federal de Minas Gerais, Universidade Nacional de Brasília, Universidade Federal do Rio de Janeiro, Universidade Federal do Paraná, Universidade Federal de Pernambuco, Universidade de São Paulo, Universidade Estadual de Campinas e Universidade Estadual Paulista.
} 
ADLER, K. H. Demography at liberation: using history to forget the past. In KITSON, S. e DIAMOND, $\mathrm{H}$. (org.). Vichy, resistance, liberation - new perspectives on wartime in France. Oxford: Berg, 2005.

AUZÉPY-CHAVAGNAC, V. La jeune droite (années 1930 et 1940): histoire d'une différence. Mil neuf cent, n. 13, p. 81-102, 1995.

BERDOULAY, Vicent. A abordagem contextual. Espaço e cultura, n. 16, p. 47-56, 2003.

BOMFIM, P. R. de A. Michel Rochefort e o Instituto Brasileiro de Geografia e Estatística na década de 1960. Sociedade \& Natureza, vol. 7, n. 3, 2015.

BOURDIEU, Pierre. Os usos sociais da ciência: por uma sociologia do campo científico. São Paulo: Editora Unesp, 2003.

BURNHAM, June. Politicians, bureaucrats and leadership in organizations - lessons from Regional Planning in France. Nova York: Palgrave Macmillan, 2009.

CHIQUITO, Elisângela de Almeida. A Comissão Interestadual da Bacia Paraná-Uruguai: do planejamento de vale aos polos de desenvolvimento. São Paulo: Tese de Doutorado Universidade de São Paulo/FAU, 2012.

COHEN, A. Du corporativisme au keynésianisme. Continuités pratiques et ruptures symboliques dans le sillage de François Perroux. Revue française de science politique, n. 56, v. 4, p. 555-592, 2006.

COUZON, I. 'Les espaces économiques' de François Perroux (1950). Organisation et aménagement du territoire dans l'économie et la géographie française au milieu du XXème siècle. Revue d'Histoire des sciences humaines, n. 9, p. 81-102, 2003.

COUZON, I. La place de la ville dans le discours des aménageurs du début des années 1920 à la fin des années 1960. Cybergeo, doc. 1997. <https://journals.openedition.org/cybergeo/1979>.

DINIZ, Clélio C. Lucas Lopes, o visionário do desenvolvimentismo. Revista do Arquivo Público Mineiro, n. 44, v .2, p. 80-95, 2008.

GEDDES, Patrick. Cities in evolution. Londres: William \& Norgate, 1915.

GRAVIER, J.-F. Régions et nations. Paris: Presses Universitaires de France, 1942.

GRAVIER, J.-F. Paris et le désert français. Paris: Portulan, 1947.

GRAVIER, J.-F. Mise en valeur de la France. Paris: Portulan, 1949.

GRAVIER, J-F. Décentralisation et progrès technique. Paris: Portulan, 1953.

GRAVIER, J.-F. Paris et le désert français. Paris: Flammarion, 1958.

JACKSON, J. "Mal embarqué bien arrivé": the strange story of François Perroux. In KITSON, S. e DIAMOND, $H$. (org.). Vichy, resistance, liberation - new perspectives on wartime in France. Oxford: Berg, 2005. 
JONES, Colin. Paris: biografia de uma cidade. Porto Alegre: L\&PM, 2017.

KROPOTKIN, P. Fields, factories and workshops. Londres: Freedom Press, [1898] 1985.

KUISEL, R. F.; FLORENTIN, M.-C. Vichy et les origines de la planification économique (1940-46). Le mouvement social, n. 98, p. 77-101, 1977.

LAFOURCADE, M. Paris et le désert français: une légende urbaine? Idées économiques et sociales, n. 167, p. 7-13, 2012.

LE BRAS, Hervé. Les 4 mystères de la population française. Paris: Odile Jacob, 2007.

LOTTMAN, H. R. A rive guache - escritores, artistas e políticos em Paris 1931-1953. Rio de Janeiro: José Olympio, 2009.

MARCHAND, Bernard. Le haine à la ville: "Paris et le désert français" de Jean-François Gravier.

L'information geographique, n.65, v. 3, p. 234-253, 2001.

MAURRAS, C. L'idée de la décentralisation. Paris: L'association des amis de la maison du chemin du Paradis, 2008.<www.maurras,net>

MURARD, L.; FOURQUET, F. La naissance des ville nouvelles: anatomie d'une décision (1961-1969). Paris: Presses de l'école nationale de ponts et chaussés, 2004.

PAXTON, R. O. Vichy France - old guard and new order - 1940-1944. Nova York: Alfred A. Knopf inc, 1972.

PHLIPPONEAU, M. La grande affaire: décentralisation et régionalisation. Paris: CalmannLévy, 1981.

POUVREAU, B. La politique d'aménagement du territoire d'Eugène Claudius-Petit. Vingtième Siècle. Revue d'histoire, n. 79, p. 43-52, 2003.

PRITCHARD, Sara B. Confluence - the nature of technology and the remaking of the Rhône. Londres: Harvard University Press, 2011.

WAKEMAN, R. Nostalgic modernism and the invention of Paris in the twentieth century. French historical studies, n. 27, v. 1, p. 115-144, 2004.

WINOCK, M.; JULLIARD, J. Dictionnaire des intellectuels français. Paris: Éditions du Seuil, 1996. 